\title{
THE
}

\section{Financial Adaptation Among College Students: Helping Students Cope with Financial Strain}

Joyce Serido

Soyeon Shim

Jing Jian Xiao

University of Rhode Island, xiao@uri.edu

Chuanyi Tang

Noel A. Card

Follow this and additional works at: https://digitalcommons.uri.edu/hdf_facpubs

The University of Rhode Island Faculty have made this article openly available.

Please let us know how Open Access to this research benefits you.

This is a pre-publication author manuscript of the final, published article.

Terms of Use

This article is made available under the terms and conditions applicable towards Open Access Policy Articles, as set forth in our Terms of Use.

\section{Citation/Publisher Attribution}

Serido, J., Shim, S., Xiao, J. J., Card, N., \& Tang, C. (2014). Financial adaptation among college students: Helping students cope with financial strain. Journal of College Student Development, 55(3), 310-316. doi: 10.1353/csd.2014.0032.

Available at: http://dx.doi.org/10.1353/csd.2014.0032

This Article is brought to you for free and open access by the Human Development and Family Science at DigitalCommons@URI. It has been accepted for inclusion in Human Development and Family Science Faculty Publications by an authorized administrator of DigitalCommons@URI. For more information, please contact digitalcommons-group@uri.edu. 
Financial Adaptation Among College Students: Helping Students Cope with Financial Strain Joyce Serido

University of Arizona

Soyeon Shim

University of Wisconsin-Madison

Jing Jian Xiao

University of Rhode Island

Chuanyi Tang

Old Dominion University

Noel A. Card

University of Arizona

Joyce Serido is Assistant Director and Research Professor in the Take Charge America Institute at the Norton School of Family and Consumer Sciences, University of Arizona. Soyeon Shim is Professor and Dean of the School of Human Ecology, University of Wisconsin-Madison. Jing Jian Xiao is Professor of Human Development and Family Studies, University of Rhode Island. Chuanyi Tang is Assistant Professor of Marketing at Old Dominion University. Noel A. Card is Associate Professor of Family Studies and Human Development at the University of Arizona.

This study has been made possible through the generous support of the National Endowment for Financial Education ${ }^{\circledR}$ (NEFE). The authors thank NEFE® for their dedication to research, education, and outreach in promoting financial literacy. We also thank the student respondents who participated in the APLUS study. 


\begin{abstract}
This study examines the impact of the recent financial crisis on co-occurring patterns of change in financial strain and financial coping behaviors of college students $(\mathrm{N}=748)$ using twotimed, longitudinal data collected prior to the 2008 financial crisis and again one year later. Using a stress and coping framework, we found that different measures of perceived change in financial strain acted as antecedents of change in types of financial coping behaviors. We discuss the importance of these findings in developing the financial decision-making skills that young adults need in an era of increasing responsibility for their financial future.
\end{abstract}

Coming of age in any generation brings with it the goal of being financially selfsufficient. Yet today's college students are transitioning to adulthood following the worst recession since the Great Depression (Wheelock, 2010)_a time of job losses, decreasing employer-provided benefits, less access to credit—and uncertain funding for social support programs. The students of this generation, and those to come, must bear more individual responsibility for securing their financial future. Financial strain, defined as financial demands that tax one's ability to manage those demands (Lazarus, 1999), is a source of stress among college students (Staats, Cossmar, \& Kaffenberger, 2007). The financial strain of credit-card debt has been associated with reduced physical and mental health (Eisenberg, Gollust, Golberstein, \& Hefner, 2007) as well as students' inability to complete their education (Hyun, Quinn, Madon, \& Lustig, 2006). On the other hand, responsible financial behaviors have been associated with positive life outcomes (Serido, Shim, Mishra, \& Tang, 2010; Shim, Xiao, Barber \& Lyons, 2009). 
Concern about the financial behaviors of college students, particularly behaviors regarding credit card use (Lyons, 2004), predates the credit crisis and has prompted research into the formation of young adults' financial behaviors. For instance, in a sample of 420 undergraduate students from six states, Jorgensen and Savla (2010) found that perceived parental influence had a significant positive effect on students' financial behaviors, mediated through positive financial attitudes. A separate study of more than 2,000 first-year students at a public university (Shim, Barber, Card, Xiao, \& Serido, 2010), found evidence that, in addition to parents' financial socialization, high school work experience and financial education classes also contributed to more responsible financial behaviors among college students. Because financial behaviors practiced in college may form the basis for financial behaviors practiced in life (Varcoe, Peterson, Swanson, \& Johns, 2010).), it is important to understand how college experiences affect young adults' financial behaviors. This may be particularly relevant in the aftermath of the 2008 financial crisis, as uncertain job prospects, mounting college loan debt, and personal responsibility for securing future financial security may force today's young adults to alter their financial behaviors to adapt to a changing environment (McEwen, 1998). Behavior changes made under stress, however, are not always adaptive (Janis, 1993). For example, to lower current expenses, a student may drop classes or take a semester off, and thus fail to graduate in four years or risk dropping out of college altogether. In the present study, we examine the relation between college students' changing financial demands and changes in their financial behaviors to cope with those demands. To our knowledge, ours is the first study to examine co-occurring patterns of change in financial strain and financial behaviors over time.

This study adopts a stress and coping framework (Lazarus, 1999; Lazarus \& Folkman, 1984) to consider financial adaptation among college students - that is, how college students 
change their financial behaviors to cope with changes in financial strain. To examine financial adaptation, the study relies on two-timed longitudinal data collected from college students $(N=$ 748) in the spring of 2008 (prior to the economic crisis) and again one year later. Financial strain is assessed by both changes in objective financial demands (e.g., debt) and changes in perceived financial strain (e.g., financial stress and impact of recession); change in three types of financial coping behaviors is assessed: reactive financial coping (e.g., cutting expenses), preventive financial coping (e.g., managing money), and proactive financial coping (e.g., saving).

\section{Conceptual Model and Adaptation Hypothesis}

A stress and coping perspective (Lazarus, 1999; Lazarus \& Folkman, 1984) posits that people modify their attitudes and behaviors in response to changing life demands, whether the demands emanate from circumstances unique to the individual—for example, a new job or a tuition increase_-or reflect more macro-level changes, such as an economic recession. From this perspective, then, the economic recession is an environmental stressor that triggers change in financial behaviors to cope with changes in financial strain. Although cross-sectional studies have found an inverse association between positive financial behaviors and financial strain (Hayhoe, Leach, Turner, Bruin, \& Lawrence, 2000; Xiao, Sorhaindo, \& Garman, 2006), longitudinal data, however, will allow us to examine co-occurring change in financial strain and financial behavior as a process of adaptation. Based on a stress and coping framework and previous cross-sectional work, we hypothesize that changes in financial strain will be associated with changes in financial behavior. Specifically, students experiencing greater increases in financial strain will report more change in financial coping behaviors.

\section{Financial Coping Behaviors}


Although coping is most often conceptualized as reactive behavior taken in response to stressful situations (Lazarus, 1999; Lazarus \& Folkman, 1984), recent studies on young adults have demonstrated that beyond reducing stress, future-oriented coping strategies may promote individual growth and thriving (Gan, Yang, Zhou, \& Zhang, 2007; Greenglass \& Fiksenbaum, 2009). Consistent with this broader view of coping and the literature in the personal finance domain (Xiao, 2008), we conceptualized three types of financial coping behaviors: (a) reactive behaviors to manage immediate changes in financial conditions (e.g., cost cutting), (b) preventive behaviors to minimize future financial strain (e.g., spending within budget), and (c) proactive behaviors to promote future goals (e.g., savings). Given the current economic uncertainty and college students' relative inexperience managing their personal finances, we wondered if the changes in their financial behaviors were adaptive, posing the following research question, "Are there different patterns of associations between changes in financial strain and changes in financial coping behaviors?"

\section{METHOD}

\section{Participants}

After receiving approval from the Institutional Review Board at the University of Arizona, we collected web-based survey data (Time 1 ; T1) from first-year college students $(N=$ $748,65 \%$ women) enrolled at the university during spring 2008 , prior to the global credit crisis, and again in spring 2009 (Time 2; T2). The majority of the students were White (67\%), followed by Latino/a (14\%), Asian/Pacific Islander (11\%), Black (3\%), and Native American (1\%). Ethnic group identification was reported as other or was missing for the remaining 4\%. Representation by parental socioeconomic status (SES), measured as parents' education and income, included 44\% lower SES, 32\% middle SES, and 24\% higher SES. 


\section{Survey Instrument}

A key objective of the study was to understand college students' perceptions of the recession on their knowledge, attitudes, behaviors, and associated impact on their well-being. The 10-minute survey comprised 78 questions, including multiple Likert-type scales about attitudes, behaviors, and well-being, true/false financial knowledge questions, and open-ended narrative about students' perception of the impact of the recession. The same questions were used in both the T1 and T2 surveys, with the exception of questions about perceived impact of the recession. Existing measures from the personal financial literature and well-being literature were used wherever possible; new measures designed for the survey were first pilot tested in similar student populations prior to inclusion in the survey (the complete survey is available upon request from the first author; see also Shim et al., 2010 for detailed information about the data collection procedure).

\section{Measures}

Change in perceived financial stress, based on respondents' agreement with three statements—-for example, I have difficulty paying for things, coefficient alpha 0.84 (T1) and 0.82 (T2) — was calculated as the difference between T1 and T2 mean scores. Measures of change in financial coping behaviors were computed as mean difference scores between $\mathrm{T} 1$ and $\mathrm{T} 2$; the categories were change in reactive financial coping (e.g., change in shopping and eating habits), change in preventive financial coping (e.g., spent within budget), and change in proactive financial coping (e.g., saved money for emergency). Debt amounts, based on students' estimate of combined educational loan, credit card balance, and other personal loan balances, were recoded into five levels: 1 (zero debt), 2 (greater than zero but less than or equal to the $M), 3(M$ plus $1 S D), 4$ (M plus $2 S D$ ), and 5 (more than $2 S D$ above $M$ ). Change in debt was calculated as 
the difference between T1 and T2 debt levels. Perceived impact of the financial crisis, designed for the T2 survey, was measured at T2 only on a three-item 5-point scale (e.g., to what extent has the recent economic decline affected the way you manage your money, coefficient alpha 0.85). The analyses controlled for both gender $($ male $=1 ;$ female $=2)$ and parental socioeconomic status.

\section{RESULTS}

To examine correlated changes in financial strain and financial coping behaviors and to assess differences in the patterns of associations, we fit a structural equation model (see Figure 1, showing the significant, unique predictions). We found that change in perceived financial stress was the most robust indicator of change in financial coping behavior, with greater increases in financial stress related to increased use of reactive behavior and decreased use of proactive behavior; conversely, greater decreases in perceived financial stress were associated with decreased use of reactive behavior and increased use of proactive behavior. Participants who reported the most perceived impact at $\mathrm{T} 2$, however, took preventive steps to manage their resources (e.g., budgeting, tracking their expenses, paying bills on time), rather than reactive steps. Changes in debt were not associated with change in any coping behaviors.

\section{<INSERT FIGURE 1 ABOUT HERE>}

\section{DISCUSSION}

A college education sets young people on a pathway to adulthood often associated with financial success. Yet increasing costs of college and an uncertain economic climate may strain a student's financial resources, triggering hasty financial decisions with a high future cost. Financial strain may interfere with students' ability to complete their education (Hyun et al., 2006). Although previous studies have examined the role of socializing agents on the formation 
of college students' financial behaviors (Jorgensen \& Savla, 2010; Shim et al., 2010), ours is the first study to examine how changes in financial demands disrupt responsible financial behaviors and how students cope with those changes. As the risks and responsibility for financial security rest on the shoulders of average Americans (Littrell, Brooks, Ivery, \& Ohmer, 2010), it is critical that college students develop responsible financial decision-making skills. Using a stress and coping framework (Lazarus, 1999; Lazarus \& Folkman, 1984), we found that college students changed their financial behaviors in response to changing financial demands. Our findings, however, demonstrate that perceived change in financial strain, but not change in objective financial debt, prompted change in financial coping behaviors.

Change in perceived financial stress was associated with increased use of reactive behaviors and decreased use of proactive behaviors; conversely, greater decreases in perceived financial stress were associated with decreased use of reactive behaviors and increased use of proactive behaviors. This pattern suggests that in the face of financial demands, students resort to expedient financial behaviors (e.g., cost cutting and borrowing) that may not be adaptive in the long run. These associations did not differ by gender or SES.

Change in debt amount was not associated with change in any of the three types of coping behaviors. Looking more closely at our data, we found that the average percentage increase in outstanding debt between T1 and T2 was less than $2 \%$ and perhaps not large enough to cause alarm among the students. Moreover, because educational loans represented the largest component of debt, students may have viewed the increase as an investment in their future (Hornak, Farrell, \& Jackson, 2010). As the costs of a college education continue to rise and students take out increasing debt to finance their education, future research on the relation of debt to both financial stress and financial coping behaviors is warranted. 


\section{Implications}

Our findings reveal, through the magnifying lens of a severe economic recession, ways that college students manage financial demands. This approach highlights the importance of developing financial coping skills prior to facing future financial demands, such as decreasing financial support from parents, purchasing new homes, and repaying student loans. As Janis (1993) points out, the cognitive impairment associated with high levels of stress may lead to "narrowing the range of perceived options, overlooking long-term consequences, inefficient searching for information, erroneous assessing of expected outcomes, and using oversimplified decision rules that fail to take account of the full range of values implicated by choice" (p. 57). Inexperience exacerbates this cognitive impairment. At first glance it may seem that students with high stress are taking the most prudent course of action: focusing on the financial demands

of the present. Yet this approach overlooks an important preventive component of personal financial management: specifically, taking present action to minimize future impact. It may be that young adults did not learn about—or were uninterested in-personal financial matters. The recent economic crisis, however, has opened a window of opportunity, where young adults are ready to learn more about personal finances (Sallie Mae, 2009).

Our findings suggest that educators, administrators, and parents can assist this generation of young adults by teaching them effective ways to manage increasing financial demands when resources are limited. Financial education taught within a stress and coping framework makes the macro-level economic events personally relevant, demonstrating how personal finances may be disrupted by external conditions (e.g., an economic recession) as well as by unexpected and increased expenses, and providing young adults with alternative approaches to managing the financial ups and downs of life. Incorporating case studies into classroom education and 
providing situational and role-playing experiences may increase awareness of responsible strategies for coping with common financial problems young adults encounter. In addition, a stress-based approach for teaching financial coping skills may serve to "inoculate" young adults against making poor financial choices when faced with the increasing financial demands of adult life (Janis, 1993).

\section{Limitations}

Although this study presents an innovative approach for understanding change in the financial behaviors of young adults, limitations merit caution in interpreting our findings. First, we relied on self-report data obtained from students, thus introducing a threat of shared reporter variance to inflate associations among variables. Future research to consider multiple informants or more objective measures of financial strain is warranted. A second limitation is more of a caution—namely, although we relied on data from the same students over time, our focus in these analyses was on co-occurring change among constructs. Because these analyses do not contain a time lag between presumed predictors and outcomes, alternative causal pathways are just as tenable. Future analyses involving more time points will allow better evaluation of which changes antecede or are consequences of other changes.

\section{Concluding Remarks}

For today's young adults, the current economic climate may play an important role in shaping financial values, attitudes, behaviors, and even life goals, possibly shifting the demographics of college enrollment and graduation. Given that college students have limited experience making personal financial decisions and because recent economic events provide a changing environment for making those decisions, this study provides a unique opportunity to examine college students' current financial coping behaviors as the basis for adult financial 
behaviors. At this time, the need for financial education and financial planning may be greater than ever before. Thus the main contributions of this study are highlighting the patterns in how young adults cope with financial strain and emphasizing the importance of helping students develop proactive coping skills. Encouraging college students to practice adaptive coping strategies may help them avoid costly errors and establish a lifelong pattern of effective financial decision-making.

Correspondence concerning this article should be addressed to Joyce Serido, phone (520) 6215820 (office), (520) 621-9445 (fax), email: jserido@email.arizona.edu 


\section{REFERENCES}

Eisenberg, D., Gollust, S. E., Golberstein, E., \& Hefner, J. L. (2007). Prevalence and correlates of depression, anxiety, and suicidality among university students. American Journal of Orthopsychiatry, 77, 534-542.

Gan, Y., Yang, M., Zhou, Y., \& Zhang, Y. (2007). The two-factor structure of future-oriented coping and its mediating role in student engagement. Personality and Individual Differences, 43, 851-863.

Greenglass, E. R., \& Fiksenbaum, L. (2009). Proactive coping, positive affect, and well-being. European Psychologist, 14, 29-39.

Hayhoe, C. R., Leach, L. J., Turner, P. R., Bruin, M. J., \& Lawrence, F. C. (2000). Differences in spending habits and credit use of college students. Journal of Consumer Affairs, 34, 113133.

Hornak, A., Farrell, P. L., \& Jackson, N. J. (2010). Making it (or not) on a dime in college: Implications for practice. Journal of College Student Development, 51(5), 481-495.

Hyun, J. K., Quinn, B. C., Madon, T., \& Lustig, S. (2006). Graduate student mental health: Needs assessment and utilization of counseling services. Journal of College Student Development, 47(3), 247-266.

Janis, I. L. (1993). Decision-making under stress. In L. Goldberger \& S. Breznitz (Eds.), Handbook of stress: Theoretical and clinical aspects (2nd ed., pp. 56-74). New York, NY: Free Press.

Jorgensen, B. L., \& Savla, J. (2010). Financial literacy of young adults: The importance of parental socialization. Family Relations, 59(4), 465-478.

Lazarus, R. S. (1999). Stress and emotion: A new synthesis. New York, NY: Springer.

Lazarus, R. S., \& Folkman, S. (1984). Stress, appraisal, and coping. New York, NY: Springer. 
Littrell, J., Brooks, F., Ivery, J., \& Ohmer, M. L. (2010). Why you should care about the threatened middle class. Journal of Sociology \& Social Welfare, 37(2), 87-113.

Lyons, A. C. (2004). A profile of financially at-risk college students. Journal of Consumer Affairs, 38(1), 56-80.

McEwen, B. S. (1998). Stress, adaptation, and disease: Allostasis and allostatic load. Annals of the New York Academy of Sciences, 840, 33-44.

Sallie Mae. (2009). How undergraduate students use credit cards: Sallie Mae's national study of usage rates and trends 2009. Retrieved from http://www.salliemae.com/NR/rdonlyres/0BD600F1-9377-46EA-AB1F6061FC763246/10744/SLMCreditCardUsageStudy41309FINAL2.pdf

Staats, S., Cosmar, D., \& Kaffenberger, J. (2007). Sources of happiness and stress for college students: A replication and comparison over 20 years. Psychological Reports, 101(3), 685-696.

Serido, J. Tang, C., Mishra, A. \& Shim, S. (2010). Family environment and its impact on college students' well-being. Family Relations, 59, 453-464.

Shim, S., Barber, B., Card, N., Xiao, \& Serido, J. (2010). Financial socialization of young adults: The role of family, work, and education. Journal of Youth and Adolescence, 39(12), $1457-1470$.

Shim, S., Xiao, J., Barber, B., \& Lyons, A. (2009). Pathways to life success: A model of financial well-being for young adults. Journal of Applied Developmental Psychology, 30, 708-723. 
Varcoe, K. P., Peterson, S. S., Swanson, P. W., \& Johns, M. C. (2010). What do teens want to know about money: A comparison of 1998 and 2008. Family and Consumer Sciences Research Journal, 38(4), 360-371.

Wheelock, D. C. (2010). Comparing the Federal Reserve's responses to the crises of 1929-1933 and 2007-2009. Federal Reserve Bank of St. Louis Review, 92(2), 89-107.

Xiao, J. J. (2008). Applying behavior theories in financial behaviors. In J. J. Xiao (Ed.), Handbook of consumer finance research (pp. 69-81). New York, NY: Springer.

Xiao, J. J., Sorhaindo, B., \& Garman, E. T. (2006). Financial behaviors of consumers in credit counseling. International Journal of Consumer Studies, 30, 108-121. 


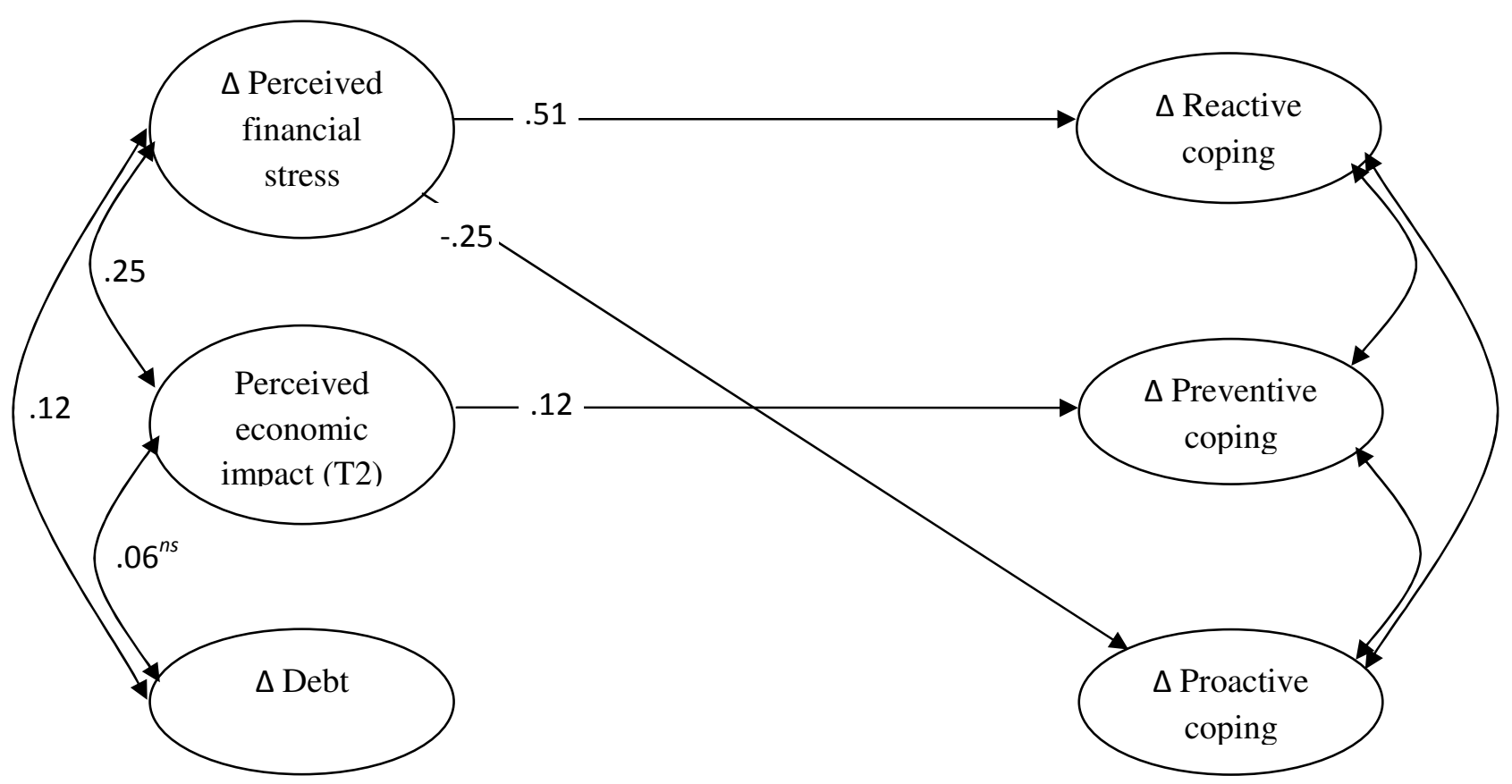

Figure 1. Structural Model of Co-occurring Change.

Note. Model fits the data well: $\chi^{2}(364, N=748)=1065.79$, RMSEA $=.051, \mathrm{CFI}=.95$. Values shown are standardized values that are statistically significant (unless noted otherwise: $n s$ ). Model controls for gender and SES. $\Delta=$ differences between Time 1 (T1) and Time 2 (T2). 